\title{
Information battleground: Conflict perceptions motivate the belief in and sharing of fake
}

\section{news about the adversary}

Mathias Osmundsen ${ }^{1 *}$, Honorata Mazepus $^{2 *}$, Antoaneta Dimitrova $^{3}$, Dimiter Toshkov $^{4} \&$ Michael Bang Petersen ${ }^{5}$

\begin{abstract}
Why do people disseminate fake news online? We investigate this question by focusing on the effect of perceived conflict on the endorsement of fake news in the context of a regional conflict between Russia and the West as experienced by Ukrainian citizens. In our survey experiment, a sample of Ukrainians $(N=1,615)$ was randomly assigned to read negative fake news stories about Russia, the European Union or Tanzania - a country with no stakes in the conflict. We find that perceived conflict between Ukraine and Russia makes Ukrainians less likely to endorse fake news targeting the European Union, but more likely to endorse fake news about Russia. This finding extends the support for motivated reasoning theory beyond Western contexts investigated so far, but also advances our understanding of why false information is disseminated and point to the importance of conflict deescalation to prevent its diffusion.
\end{abstract}

\footnotetext{
${ }^{1}$ Department of Political Science Aarhus University, Bartholins Allé 7, Aarhus, Denmark. m.osmundsen@ps.au.dk

${ }^{2}$ Institute of Public Administration, Leiden University, h.mazepus@ @gga.leidenuniv.nl

${ }^{3}$ Institute of Security and Global Affairs, Leiden University, a.l.dimitrova@ @gga.leidenuniv.nl

${ }^{4}$ Institute of Public Administration, Leiden University, d.d.toshkov@ fgga.leidenuniv.nl

${ }^{5}$ Department of Political Science and Institute for Advanced Studies, Aarhus University, michael@ ps.au.dk.

* These authors contributed equally to this work and are corresponding authors.
} 
The circulation of political misinformation and "fake news" on social media has emerged as a major societal concern. But why do citizens contribute to the dissemination of falsehoods online? In American politics, scholars increasingly focus on how deepening political divides drive partisans toward uncritical sharing of dubious and often misleading claims about political opponents (Grinberg et al. 2019; Guess et al. 2019). However, domestic cleavages such as electoral fights between Democrats and Republicans are not the only conflict lines that can cause falsehoods to spread. Reminiscent of the Cold War, Russia stand accused of weaponizing fake news to interfere with elections in America, France, and Great Britain (e.g., Silverman 2016; Oates, 2017) and for flooding Eastern Europe with online disinformation to drive down support for the European Union and NATO (e.g., Fredheim, 2015; Oates, 2016). Such digital disinformation campaigns reflect deeper geopolitical cleavages and contribute to intensified conflict across country borders. Nonetheless, we know little about how experiencing such conflicts affects citizens' vulnerability to falsehoods. That is, who among the public will believe and share false information about actors involved in regional and international conflicts?

The theory of motivated reasoning offers a compelling framework for answering these questions. It posits that people accept information that supports their preexisting beliefs and, conversely, reject and counter-argue information that challenges those same beliefs (Kunda 1990). This insight has shown substantial promise in explaining how - in the context of American politics - identities linked to political parties propel citizens to believe and share misinformation, fake news, and conspiracy theories that reflect favorably on their political side (e.g., Guess et al. 2019; Miller et al. 2016).

Our first contribution is to examine whether the theory of motivated reasoning extends to explaining beliefs in misinformation in Eastern Europe. As we will argue, Eastern Europe differs significantly from the context of American politics, both in terms of its historical legacy with 
communism, but also regarding the intensity of geopolitical conflict between foreign actors - most notably, the European Union and Russia. How well, we ask, does the theory help us makes sense of how Eastern Europeans reason about fake news about such international actors?

Our second contribution is to identify who is most likely to engage in motivated reasoning in the context of this study. The power of political identity in influencing one's beliefs is not a fixed feature of human psychology; context matters (Groenendyk and Krupnikov 2021). As conflicts escalate, the gulf between competing groups will naturally widen, making it vital for people to stand fast and shield their political group from attacks by outgroups. On the flip side, harmonious times under which groups peacefully coexist will likely loosen the need to ardently defend the standing of one's group. This argument, we contend, suggests that perceptions of group-based conflict are critical drivers of motivated reasoning. When perceptions of conflict are low, people will hesitate to believe and share misinformation about other groups. When perceptions of conflict run high, people will be more strongly endorse misinformation about rival groups.

We test our theory among citizens of Ukraine. Located in Eastern Europe, Ukraine has strong historical and cultural ties to Russia. However, following the Euromaidan revolution - a wave of pro-European protests culminating with the overthrow of the pro-Russian government and president-elect Viktor Yanukovych -- and the subsequent annexation of Crimea in 2014, the relation between Ukraine and Russia has deteriorated (e.g., Fredheim, 2015; Oates, 2016). This has become readily apparent in recent Russian efforts at sowing unrest among Ukrainians by spreading propaganda and misinformation (Sokol, 2019), best illustrated by the dissemination of Russiansponsored fake news about the perpetrators of the Malaysian Airlines Flight 17 crash over Ukraine (Golovchenko et al., 2018). Ukraine, on its side, has sought to balance against these threats of Russian interference by founding organizations like StopFake.org, which attempts to expose fabricated stories propagated by Kremlin, and by passing laws restricting Russian broadcasting news. These counter- 
strategies notwithstanding, Ukrainian public opinion is characterized by a deep social cleavage pitting a pro-Western/anti-Russian segment of the public against an opposing camp who views Russia as a bulwark against "Westernization" (Pew 2017). Empirically, this sharp divide in views about Russia versus the European Union offers an opportunity for examining if endorsement of fake news about hostile actors depend on citizens' conflict perceptions.

We test our claims using a survey experiment that randomly assigns a sample of Ukrainians to read negatively framed fake news stories about either Russia, the European Union or Tanzania - a country with no stakes in the ongoing regional conflict. Our findings show that the theory of motivated reasoning extends to fake news endorsement in Ukraine and make clear that the theory has significantly broader scope than previously demonstrated. We show that higher levels of perceived conflict between Ukraine and Russia makes Ukrainians less willing to believe and share fake news targeting the European Union and more likely to endorse fake news that paint a negative picture of Russia. Accordingly, our findings speak to current debates about the challenges of countering fake news. Because susceptibility to fake news stems from conflict perceptions, it may prove impossible to change this susceptibility without addressing the underlying causes of the adversarial relationship between the European Union and Russia. In the following sections, we first engage with a broader literature on the psychology of fake news before presenting our theoretical contributions to this literature. We then present our study and our analysis. We close by discussion the implications of our findings.

\section{Motivated Reasoning and the Psychology of Fake News}

Fake news can be defined as "fabricated information that mimics news media content in form but not in organizational process or intent" (Lazer et al. 2018). While this definition is straightforward, the everyday task confronting citizens of distinguishing between fake and true can be daunting. As fake news mimic the features of true news, a person browsing the internet for news can rarely tell whether 
a given story is true or false, but will instead have to draw on indirect cues such as source reputation, endorsements by trusted others or simply a gut feeling. Accordingly, from a psychological perspective, fake news can be seen as equivalent to a broader class of information: Rumors. Rumors are "claims of fact - about people, groups, events and institutions - that have not been shown to be true, but that move from one person to another and hence have credibility not because direct evidence is known to support them, but because other people seem to believe them" (Sunstein 2009, 6). Rumors acquire power and become socially meaningful because people willingly spread them in everyday interactions with family, friends and coworkers, and - more recently - in larger networks on social media.

Why do people believe and share unsubstantiated information like rumors and fake news? One view - which guides prominent efforts to fact-check and inoculate citizens against falsehoods (Van der Linden, Roozenbeek \& Compton 2020) - claims that people want to read, believe and share accurate information but lack the cognitive resources or time to weed out untrue information in favor of true information. This account certainly has merit: Sophistication and cognitive reflection have been shown to drive down beliefs in unsubstantiated claims (e.g., Berinsky 2012, Uscinski and Parent 2014; Pennycook and Rand, 2019). However, when it comes to politics, people may not merely be motivated by the desire to get the facts right.

The theory of directional motivated reasoning has become a dominant approach for explaining citizens' political behavior (e.g., Kunda 1990; Taber and Lodge 2006). It states that rather than carefully evaluating information, people are "biased" information processors. They willingly accept information that bolster their worldviews, but resist information that contradicts their views. In American politics, the scholarly consensus is that political identities - partisanship, in particular strongly influence citizens' reactions to information (Grinberg 2019; Guess et al. 2019). Strong partisans will enthusiastically embrace news praising the "in-party" for its glorious deeds or accusing 
the "out-party" for its appalling actions, while brushing aside inconvenient information conflicting with the in-party's interests. In offline and online political discussions, the reasoning goes, toeing the party line by sharing dubious information that helps one's party is preferred to sharing true information that reflects badly on one's side. Accordingly, the theory of directional motivated reasoning explains why people often fall for fake news, rumors, conspiracy beliefs, and other factually unsubstantiated claims that benefit their in-group (e.g., Berinsky 2017; Miller et al. 2016).

However, two outstanding issues warrant further consideration. The first concerns generalizability. Studies of motivated reasoning are overwhelmingly WEIRD ${ }^{6}$ (Henrich 2020), the bulk of studies being conducted in America among American respondents and studying the effects of partisanship on electoral politics (for notable exceptions, see Nyhan and Zeitzoff 2018; Silverman, Kaltenthaler, Dagher 2021). But can such findings based particular samples of people generalize to the broader human experience? Historical experiences and political culture leave imprints on fundamental psychological traits, norms, beliefs, attitudes, and so on, that are relevant for political scientists (Henrich, Heine, Norenzayan 2010). Accordingly, more evidence from diverse regions is needed to establish the generalizability of motivated reasoning processes. This is not to claim that, say, Eastern Europeans process information radically different than Americans do. ${ }^{7}$ But evidence from a non-Western region with a strong legacy of communism that struggles with democratization and regional conflicts offers an important test case for a general theory about human psychology.

A second issue concerns the situations in which motivated reasoning drives fake news endorsement. Group identities - such as partisanship or national identity -- may be necessary precursors of motivated reasoning. But they are unlikely to tell the whole story. For example, not all loyal Republicans believe fake news about Democrats, and even the most devoted Democrats will

\footnotetext{
${ }^{6}$ WEIRD is an acronym for Western, Educated, Industrialized, Rich, and Democratic countries.

${ }^{7}$ Indeed, in line with motivated reasoning theory, a recent study by Szostek (2017) demonstrated that Ukrainians who identified strongly with their home country were less persuaded by pro-Russian, anti-Western propaganda narratives.
} 
sometimes reject anti-Republican narratives (e.g., Uscinski, Klofstad, and Atkinson 2016). Accordingly, researchers increasingly argue for a "conditional approach" emphasizing how contextual factors influence the link between group identities and motivated reasoning (Groenendyk and Krupnikov 2021). Many such conditional factors likely exist. But the one most relevant for our purposes concerns perceptions of group conflict (Druckman et al., 2013). We propose that a framework for explaining the effects of motivated reasoning on endorsement of political fake news must account for the role conflict perceptions play in driving up or down fake news uptake.

\section{Conflict Perceptions and Fake News Endorsement}

Misinformation runs rife during periods of elevated threat and group conflict. During the Cold War, many Americans quickly adopted conspiracy theories about the Soviet Union and the alleged subversive activities of communists (Uscinski \& Parent 2014). In insurgency-affected areas of Thailand and the Philippines, perceptions of threat have led people to adopt "dread" rumors "that forecast feared or calamitous consequences (for example, the other side is winning and when they assume power, they are going to kill us all)" (Greenhill and Oppenheim 2017,3). These examples are not isolated instances. In their study of intergroup violence, Horowitz and Varshney (2003, 5) convincingly demonstrated that "rumors of aggression committed by members of targeted ethnic groups are nearly universal in events that precede deadly ethnic riots."

Moreover, the content of rumors circulated during conflicts is extremely similar across time and space. These rumors are nearly always extreme and aim to "threaten individuals through their group identities" (Bhavani, Findley, and Kuklinski 2009, 877). Such themes also feature prominently in most contemporary political fake news stories. In an increasingly polarized political climate in America (e.g., Iyengar et al. 2012), fake news often include hyper-partisan frames and narratives denigrating the out-party at the expense of the in-party (Osmundsen et al. 2021). Similarly, during the 2014 Russo-Ukrainian crisis and the annexation of Crimea, fake news promulgated by 
Russia often featured extreme and hostile narratives about Ukraine, including a dramatic (false) story about the alleged crucifixion of a baby by Ukrainian troops (Szostek 2017).

Why does misinformation about enemy groups spread rapidly during intergroup conflict? Psychological perspectives highlight the strategic role of rumor dissemination for coordinating group-based actions (Petersen, 2020). During intergroup conflicts, a crucial task is to convince fellow group members to coordinate against the rival group and to persuade third-party actors to join their cause. Hostile rumors about enemy groups are instrumental in such mobilization processes. They provide a "unifying narrative of a terrifying enemy" that allows groups to "close ranks, staunch losses, overcome collective action problems, and sensitize minds to vulnerabilities" (Uscinski and Parent 2014, 132). In fact, because rumors often contain difficult-to-verify claims about adversary groups and their leaders, they may hold an advantage over true information in coordinating and mobilizing the in-group against perceived out-group enemies (Petersen, 2020).

These observations add an important qualifier about when group-centered motivated reasoning turns on and affects how people process fake news and other hostile rumors. People do not unconditionally believe and share fake news consistent with their group identities. The effects will wax or wane depending on a person's perceptions of conflict between in- and out-group. The distinction between in-group identity and inter-group conflict perceptions is not purely semantic. People who identify strongly with a social group - be it a political party, an ethnic group or a nation - will often be friendly disposed towards other groups, in which case they have no incentive to endorse information that can harm them. In fact, the potential blows to one's social reputation associated with sharing news that turn out to be false may make them less willing to share such information (Altay et al., 2020). On the other hand, when group conflicts intensify and turn hostile, motivations to process information in a group-protective manner increase and people become more 
willing to endorse fake news that portray rival groups negatively. It is these predictions we now set out to empirically test.

\section{Overview of the Present Study}

We test our arguments in a survey experiment among Ukrainian participants. As discussed in the Introduction, Ukraine has deep historical ties with Russia. But a string of recent events - most notably, the Orange Revolution in 2004, the Euromaiden protests and the Russian annexation of Crimea in 2014 - has trapped the two countries in an intense geopolitical conflict. Today, Ukraine is considered a battleground state for Russia's information war against the West, with researchers carefully detailing how Russian official narratives frame large-scale protests in Ukraine -- be it against corruption, against electoral fraud, or for European integration - as Western-supported attacks on the sovereignty and territorial integrity of countries in Russia's neighborhood (Frear \& Mazepus 2021). The sharp divide in views between the pro-Western/anti-Soviet and anti-Western/pro-Russian parts of the Ukrainian public (Chaisty \& Whitefield 2020) presents a promising opportunity for testing the generalizability of the theory of motivated reasoning.

Our argument has important implications for which kinds of fake news Ukrainians find attractive. It predicts that Ukrainians who believe Russia and Ukraine are trapped in a hostile conflict should refrain from endorsing fake news about the European Union - Russia's main "competitor" in the region - but accept fake news that portray Russia negatively. In contrast, perceptions of conflict between Russia and Ukraine should not affect the willingness to believe and share fake news about groups of actors not involved in the regional conflict. Finally, conflict perceptions should remain a robust predictor of fake news endorsement after having accounted for the strength of Ukrainian identity - the main factor highlighted in previous accounts of motivated reasoning.

We did not pre-register the study hypothesis. But the research design and the operationalization of the key theoretical constructs presented below were based on a pilot study from 
2017, conducted among 586 participants from Belarus, Moldova, and Ukraine. We discuss the details of this pilot study in the Supplemental Materials. Briefly, the study showed that perceptions of conflict between the participants' home countries and Russia predicted the likelihood of believing actual false news about Russia. While these findings support our theoretical expectations, the study suffered from a series of shortcomings in terms of the materials used that challenge the ability to draw firm causal conclusions.

\section{Design}

We collected experimental survey data from a representative sample of the Ukrainian population between 18 and 55 years of age living in urban settlements (> 50,000 inhabitants). The online sample was recruited by the local survey agency, Info Sapiens, in December 2020. The survey was administered in Russian and Ukrainian. The sample included 1,615 participants. Of these, 828 were females, the median age was 36 years $(\min =18, \max =55), 75 \%$ were employed at the time of the study, while $72 \%$ had completed a high education.

Within the survey, participants first read an introductory prompt and gave consent to participate. Then, they answered a series of demographic questions and questions related to their perceptions of conflict between Ukraine, on the one hand, and Russia and the European Union, on the other hand. Next, participants were randomly assigned to one of two treatment conditions or a control condition. In each condition, participants were asked to read three fake news story headlines about either Russia, the European Union or, in the control condition, Tanzania. They then indicated whether they believed and wanted to share the stories. Finally, following a series of questions unrelated to the present study, participants were asked to state their identification with Ukraine, Russia and the EU. 


\section{Treatment stories and dependent variables}

Our survey experiment randomly assigned participants to one of three conditions. Each condition asked participants to read three news story headlines. The story headlines were kept identical across conditions except for the actors involved in the story. As seen in Table 1, the story headlines in the two treatment conditions described how either Russia or the European Union had taken actions that adversely affected Ukrainian citizens - e.g., by testing COVID-19 vaccines on poor Ukrainian villagers, by passing new discriminatory regulations making it easier to fire Ukrainian workers, or by funding violent street gangs roaming the streets of Kharkiv, Ukraine. The control condition asked participants to read the same headlines, this time about Tanzanian authorities behaving aggressively towards citizens of Congo. All headlines were made up by the authors for the study. For each story, participants were asked to "[i]magine you come across this headline on a news website," and they were asked to assess on 10-point scales ranging from "not likely at all" to "very likely" whether they believed the headlines and whether they would share them with people in their social networks. Answers to these questions about (1) beliefs in and (2) intentions to share the fake news stories were averaged across the three headlines. The resulting two scales comprise the study's dependent variables.

Why these news story headlines? First, as the headlines were fabricated but presented as information people could find on news websites, they fit the definition of fake news introduced earlier. Second, the stories concerned issues (e.g., COVID-19) that were meaningful to the participants at the time of the study. Third, the stories reflected the types of hostile events we expected to be prominent during inter-country conflicts. Further, while our study mainly focuses on the relationship between Ukraine and Russia, the EU headlines were important for testing the contextspecificity of conflict perceptions. The annexation of Crimea in 2014 and the subsequent military conflict in the Eastern regions of Ukraine were a direct consequence of citizens' protests calling for 
the Ukrainian government to sign the Association Agreement with the European Union. This was the culmination of a long-standing division within the Ukrainian society about choosing a pro-European rather than a pro-Russian course for their country (Chaisty \& Whitefield 2020). Accordingly, we expected that higher levels of perceived conflict between Ukraine and Russia would make people readily accept negative fake news about Russia, but less likely to endorse fake news painting a negative picture of the EU.

A similar logic guided the decision to include the headlines about Tanzania and Congo in the control condition. Neither of the two countries play an important role in current Eastern European political affairs. For this reason, participants were unlikely to have strong opinions nor great knowledge about Tanzanian-Congolese relations. As such, the control group stories represented a set of "placebo" fake news where participants' endorsement of the stories should not depend on their perceptions of conflict between Ukraine and Russia. 
Table 1. Overview of treatment materials.

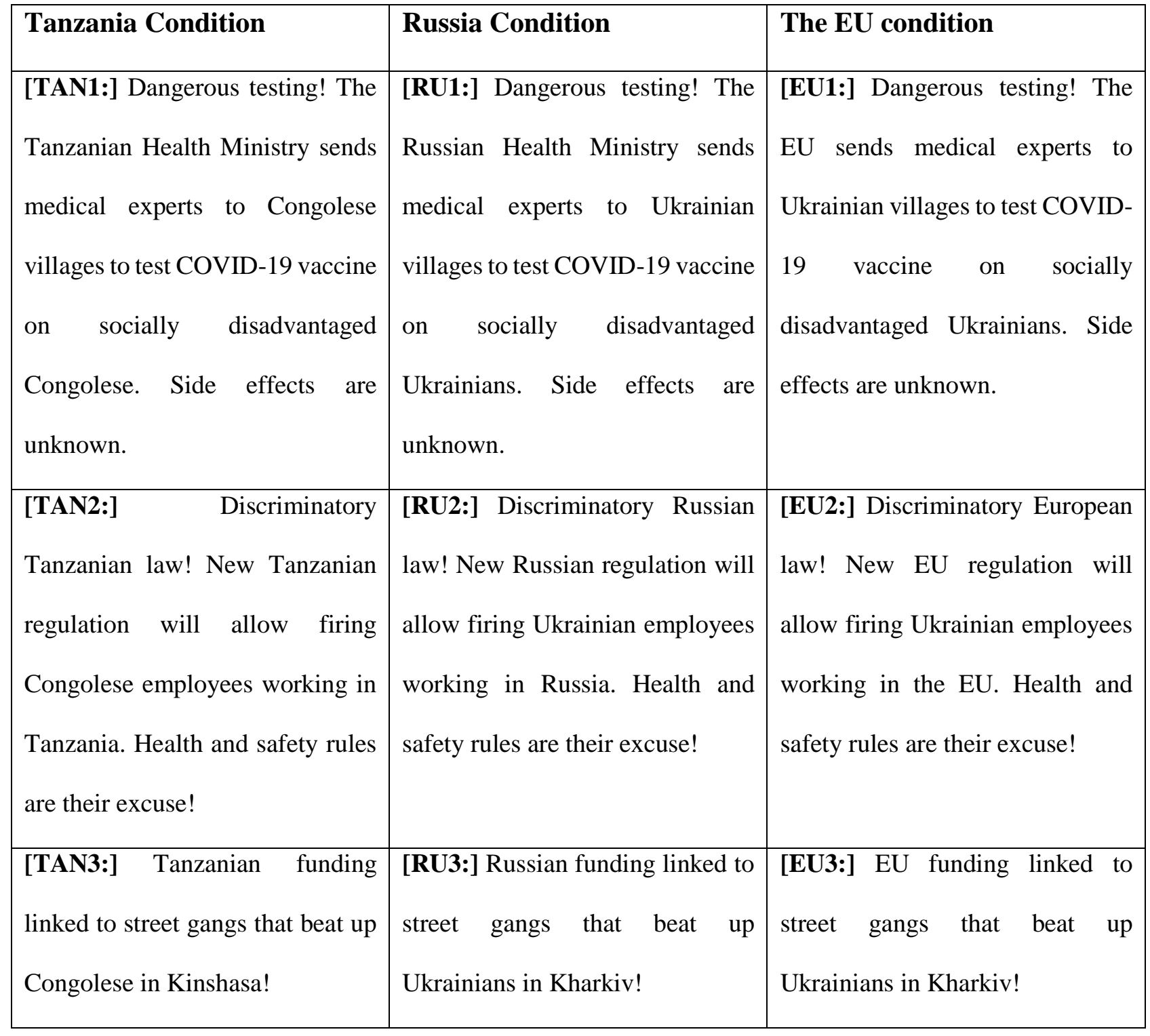

\section{Independent variables}

Perceptions of conflict. At the start of the survey, participants were on 10-point scales whether they disagreed or agreed $(0=$ Fully Disagree to $10=$ Fully agree $)$ with two statements, "Russia [/The European Union] and Ukraine have very different interests; what is good for Russia [/The European Union], is bad for Ukraine". The variables were scaled to range from 0 to 1 , with higher values indicating more intense perceptions of conflict. Participants generally held more favorably views of the EU: Perceptions of conflict between Ukraine and Russia were substantially higher $(M=0.63, S D$ 
$=0.31)$ than perceptions of conflict between Ukraine and the $\mathrm{EU}(M=0.42, S D=0.29)$. As expected, perceptions of conflict with Russia correlated negatively with EU conflict perceptions $(r=-0.20)$. In the main analysis, we focus on the measure of Ukraine-Russia conflict perceptions. The Supplemental Materials present analyses using the measure of perceived conflict between Ukraine and the EU, which we also briefly return to below.

Covariates. The models presented below adjust for a set of covariates, the most important being strength of group identity. Group identities play a decisive role in virtually every study of politically motivated reasoning. Likewise, the strength of in-group identification likely relates to perceptions of intergroup conflict as well. Accordingly, to justify our theoretical framework, we must demonstrate that conflict perceptions remain associated with fake news endorsement after accounting for the strength of group identity. Our survey included measures of identification with the central groups involved in the regional conflict: Ukraine, Russia and the EU. To measure the strength of Ukrainian [/Russian/European] identity, we averaged participants' agreement with two statements, “I consider myself Ukrainian [/Russian/European]" and "I identify with Ukraine [/Russia/Europe]". We recoded the scales to range from 0 to 1 , with higher values indicating stronger identification with the respective groups. Not surprisingly, participants identified much more strongly with Ukraine $(\mathrm{M}=.87, \mathrm{SD}=$ $.22)$ than Russia $(\mathrm{M}=.21, \mathrm{SD}=.30)$, with European identification $(\mathrm{M}=.60, \mathrm{SD}=.32)$ falling in between. The main analysis uses the measure of Ukrainian identity. The Supplementary Materials show results when adjusting for the two other identification measures.

Second, we adjust for perceptions of power asymmetry. Uscinski and Parent (2014), and Miller et al. (2016) propose that members of the losing side of a power struggle will more readily endorse rumors about enemies perceived to be powerful. In contrast, our framework predicts that conflict perceptions will predict fake news uptake even after accounting for the current balance of power between groups. To measure perceptions of power asymmetries, participants were asked on 
10-point scales whether they disagree or agree with the statement, "Russia [/The European Union] is stronger than Ukraine". We recode the scales to range from 0 to 1 , with higher values indicating that Russia/the EU is stronger than Ukraine. Participants generally agreed that Ukraine was weaker than the $\mathrm{EU}(\mathrm{M}=.83, \mathrm{SD}=.24)$ and - to a lesser extent $-\mathrm{Russia}(\mathrm{M}=.64, \mathrm{SD}=.32)$. The main analysis uses the measure of perceived power asymmetries between Ukraine and Russia, relegating the analysis of Ukrainian-European power asymmetries to the Supplemental Materials.

Third and finally, we adjust for basic demographic variables - gender, age, level of education and employment status - political interest, and political knowledge. Political knowledge which plays an important role in some theories about fake news endorsement -- was measured by summing responses to ten factual questions about politics (e.g., "Is Ukraine a member of the Eurasian Economic Union?", "How long is the term of the president of Ukraine?"). The median number of correct responses was seven.

\section{Results}

We first consider the average treatment effects of the headlines on the two main outcomes: (1) the likelihood of believing and (2) sharing the fake news headlines. Both outcomes are recoded to range from $0=$ Not likely at all to $1=$ Very likely.

How should reading fake news headlines about the EU, Russia or Tanzania affect the overall belief and intention to share those same headlines? Our theory does not explicitly make predictions about the average treatment effect. However, we saw earlier that the study participants were more friendly disposed towards the EU than Russia. Accordingly, if conflict perceptions drive fake news uptake, then on average participants should be more likely to believe and share fake news about hostile Russian actions than about the EU. As our survey did not include measures of conflict perceptions between Ukraine and Tanzania -- or between Tanzania and Congo - we leave open for now the question of how the "Tanzania" condition affects fake news endorsement. 
Taken together, Fig. 1 supports our first set of expectations. The figure's left panel of reveals that participants reading about the EU were less likely to believe the headlines $(M=.29, S D$ $=.23)$ compared to participants who read the negative fake news about Russia $(M=.42, S D=26)$ and Tanzania $(M=.44, S D=.23)$. These differences are substantially large and statistically significant $\left(\left|\beta_{\mathrm{EU}}-\mathrm{RUS}\right|=.15, \mathrm{p}<.001 ;\left|\beta_{\mathrm{EU}-\mathrm{TAN}}\right|=.13, \mathrm{p}<.001\right)$. Participants, it appears, consider fake news more believable when it targets actors they view unfavorably, even as the story content remains constant across conditions. Further, participants were more willing to believe the negative stories about Russia compared to the stories about Tanzania. While this difference does not reach conventional levels of statistical significance $\left(\left|\beta_{\text {RUS-v-TAN }}\right|=.02, p=.09\right)$, it again suggests that people are biased towards believing negative information about perceived adversaries compared to actors who they do not have strong opinions about.

What about intentions to share fake news? The right-hand panel shows the results. Note first that the treatment conditions generally failed to produce large differences in sharing intentions: Across conditions, sharing intentions were very similar and lower than beliefs the stories were true $\left(M_{\mathrm{EU}}=.30, S D_{E U}=.29 ; M_{T A N}=.28, S D_{T A N}=.28 ; M_{R U S}=.34, S D_{R U S}=.27\right)$. This suggests that people refuse to share information, even when they believe it is true; a finding that is corroborated by a modest correlation between beliefs and intentions to share the headlines, Pearson's $r=.62$. That said, in line with our argument, participants were significantly less likely to share fake news about the EU compared to Russia $\left(\left|\beta_{\mathrm{EU}-\mathrm{RUS}}\right|=.05, \mathrm{p}<.01\right)$. Interestingly, the Tanzanian fake news stories were the least likely to be shared. This latter finding may reflect considerations about newsworthiness -- or the lack thereof. When deciding what to share, people will likely make educated guesses about how their social network will receive the message: will people find the story amusing, interesting, instructive, or otherwise important (Altay, Hacquin, and Mercier 2020)? In this light, stories about Tanzania and Congo may simply be less relevant for an Eastern European audience to share. 
Taken together, the first results support our theory that conflict perceptions influence beliefs and intentions to share fake news. Still, the strongest test of our argument examines the extent to which conflict perceptions condition the effects of the story on beliefs and sharing intentions. It is to this test we now turn.
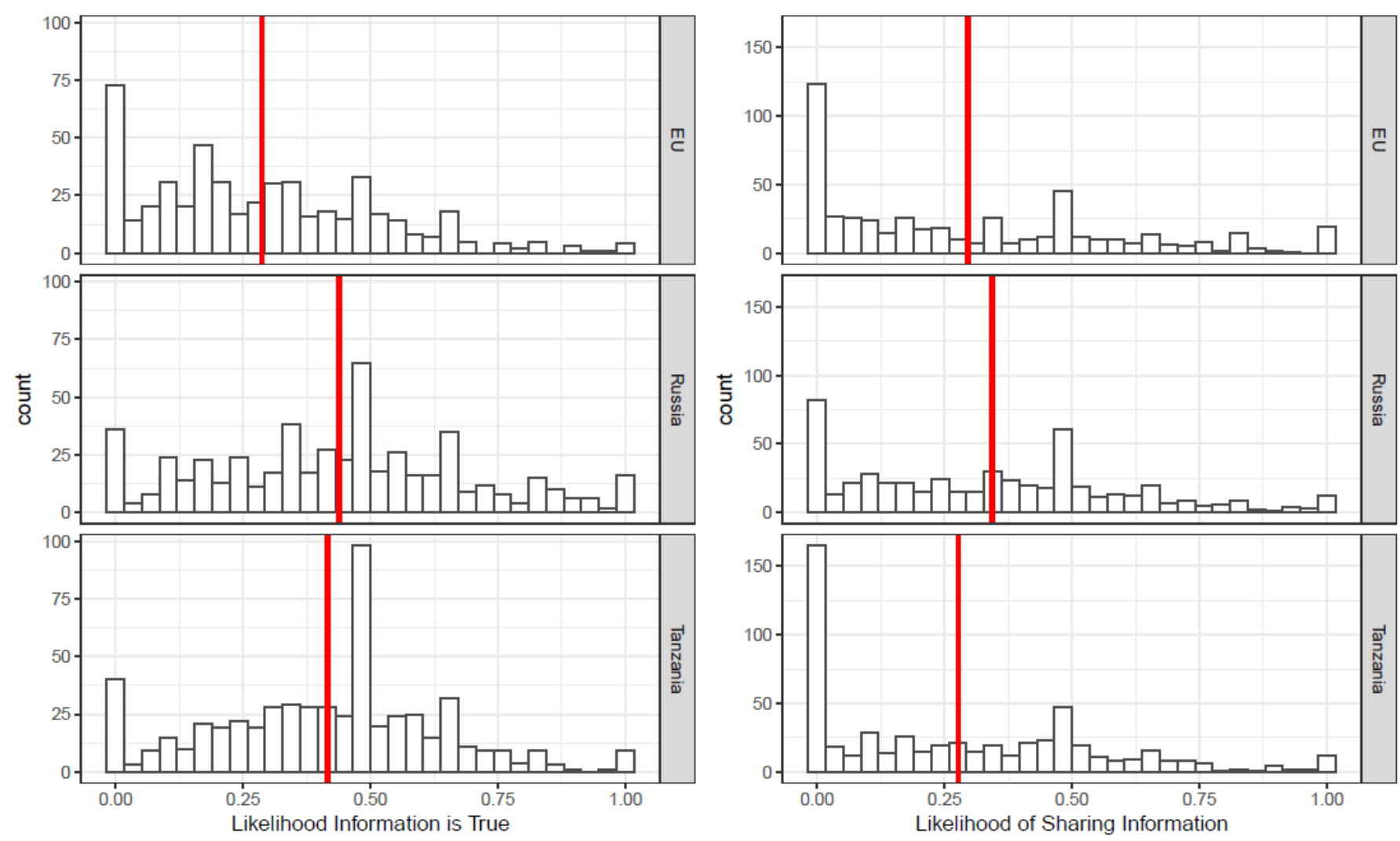

Fig. 1. Distribution of beliefs (left) and intentions to share (right) the fake news stories by treatment condition: Stories about the EU (top), Russia (middle), and Tanzania (bottom). The red vertical lines give the average value of dependent variables for each condition. The dependent variables range from 0 to 1 , with higher values indicating greater beliefs the stories and true and higher intentions to share them.

Our key hypothesis is that conflict perceptions affect fake news endorsement, and that the direction and size of the effect will depend on which actors are depicted in the stories. Empirically, three patterns should emerge. First, as perceptions of conflict between Ukraine and Russia grow stronger, the motivation to believe and share fake news about Russia should increase. Second, due to 
the antagonistic relationship between Russia and the EU - at least as perceived by many Ukrainians - stronger conflict perceptions should drive down endorsement of fake news about the EU. Third and finally, as neither Tanzania nor Congo play a role in Eastern European political affairs, perceptions of conflict between Ukraine and Russia should not influence endorsement of these stories.

We examine these predictions by, first, regressing participants' beliefs in fake news on the treatment conditions, perceptions of conflict between Ukraine and Russia, and the interactions between treatments and conflict perceptions. Additionally, the model adjusts for the covariates described previously - age, gender, educational level, employment status, political interest, political knowledge, Ukrainian identification, and perceptions of power asymmetries between Russia and Ukraine - as well as the interactions between treatment conditions and the covariates. We present the key results in Fig. 2. It shoes the predicted values of believing the headlines for the three treatment conditions, conditional on conflict perceptions between Ukraine and Russia. The Supplemental Materials present the regression tables used to construct this figure and the ones that follow.

Fig. 2 supports our expectations. Consider first the association between conflict perceptions and beliefs in fake news about Russia (blue line). As perceptions of conflict between Ukraine and Russia increase from the lowest to the highest level, beliefs in the Russian fake news headlines increase by 25 percentage points, from around .25 to .53 on the $0-1$ scale. This association, which is statistically significant $(\mathrm{p}<.001)$, shows that conflict perceptions strongly predict how people view the credibility of information about perceived adversaries. Importantly, results for beliefs in fake news about the EU (red line) reveal the opposite pattern. The downward sloping line demonstrates that beliefs in negative fake news about the EU drop considerably among participants with strong Ukrainian-Russian conflict perceptions. While this association is weaker than before moving from the lowest to the highest level of conflict perceptions is associated with a 12 percentage point decrease in believing the EU fake news $(\mathrm{p}<.001)$ - it again support our expectations about the 
conditionality of conflict perceptions. People appear to keep track of the alliances of actors in conflict situations, and these perceptions about group alignments map into beliefs about information credibility.

Results from the Tanzanian stories strengthen the conclusion about the contextspecificity of conflict perceptions. The nearly horizontal green line in Fig. 2 demonstrates that conflict perceptions are irrelevant for believing the Tanzanian fake news: irrespective of the level of perceived conflict, the predicted belief in the fake news headlines hovers around $.40(\mathrm{p}>.40)$. This finding shows that conflict perceptions do not motivate people to uncritically accept all sorts of unsubstantiated claims. Rather, they matter only for beliefs in fake news that are relevant for that specific conflict. Accordingly, whether or not a news story is deemed true or false not only depends on its objective truth-value, which we keep constant here. It also depends on the fit between story content and perceived patterns of conflict. 


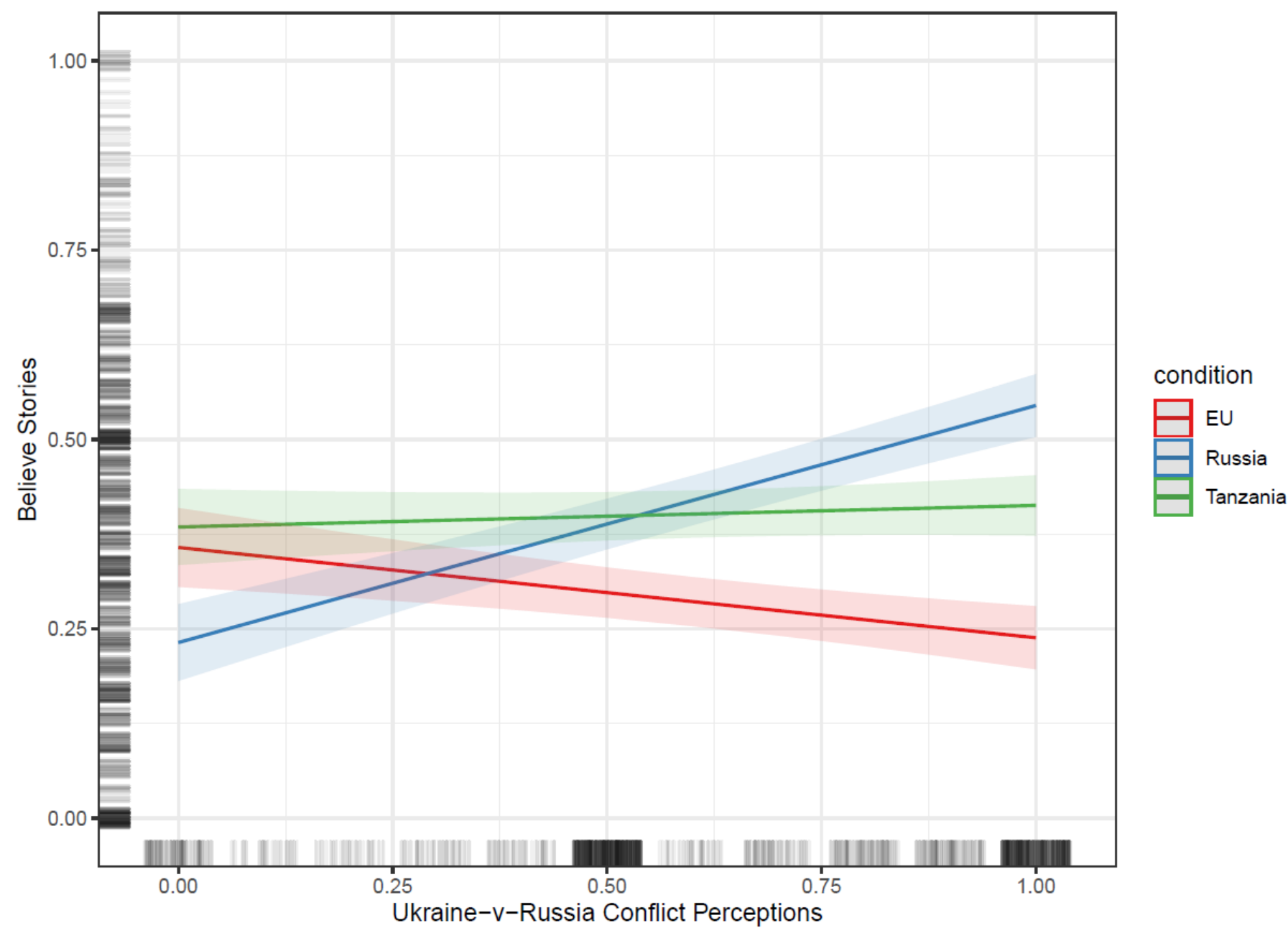

Fig. 2. Predicted values of believing the fake news stories with $95 \%$ confidence intervals by treatment condition -- the EU (red), Russia (blue) and Tanzania (green) -- across the range of conflict perceptions between Ukraine and Russia. Predicted values are based on OLS regression models. The vertical and horizontal lines to the left and at the bottom present the jittered distribution of the dependent variable and conflict perceptions, respectively. Conflict perceptions between Ukraine and Russia range from 0 to 1 , with higher values indicating stronger perceptions of conflict. The dependent variable range from 0 to 1 , with higher values indicating stronger beliefs the stories are true. The model adjusts for age, gender, educational level, employment status, political interest and Ukrainian identification, and perceptions of Russian power as well as the interactions between treatment conditions and the covariates.

Do perceptions of conflict also condition intentions to share the headlines? To examine this question, we estimate the same regression model except we now switch to sharing intentions as the dependent variable. The results are presented below in Fig. 3.

The results are very similar. The associations are generally weaker - which is unsurprising given the smaller average treatment effects on sharing intentions - but we observe a 
pattern in which higher Ukrainian-Russian conflict perceptions are associated with increased intentions to share anti-Russian fake news $(\beta=.19, \mathrm{p}<.001)$ but decreased intentions to share the EU fake news $(\beta=-.07, p=.09)$. While the latter finding is statistically insignificant, the overall picture seems clear: conflict perceptions not only turn up or down beliefs in fake news about perceived enemies and allies, they also condition intentions to share those same stories. As fake news in the digital world gain power in part because people willingly share them with friends and followers on social media, this is an important finding that we return to in the Discussion. Additionally, conflict perceptions do not condition the impact of the conflict-irrelevant fake news stories about Tanzania (b $=-.00, \mathrm{p}>.70)$. This again is consistent with our theory.

Finally, to test the generalizability of this pattern, we ask: Do perceptions of conflict between Ukraine and the EU (rather than Russia) also affect the willingness to believe and share the headlines? Analyses in the Supplemental Materials show that participants who view the UkrainianEuropean relationship as conflictual are much more inclined to believe and share anti-EU fake news narratives but are less willing to endorse Russian fake news. These results too align with the theory that conflict perceptions drive endorsement of fake news across different perceived adversaries. 


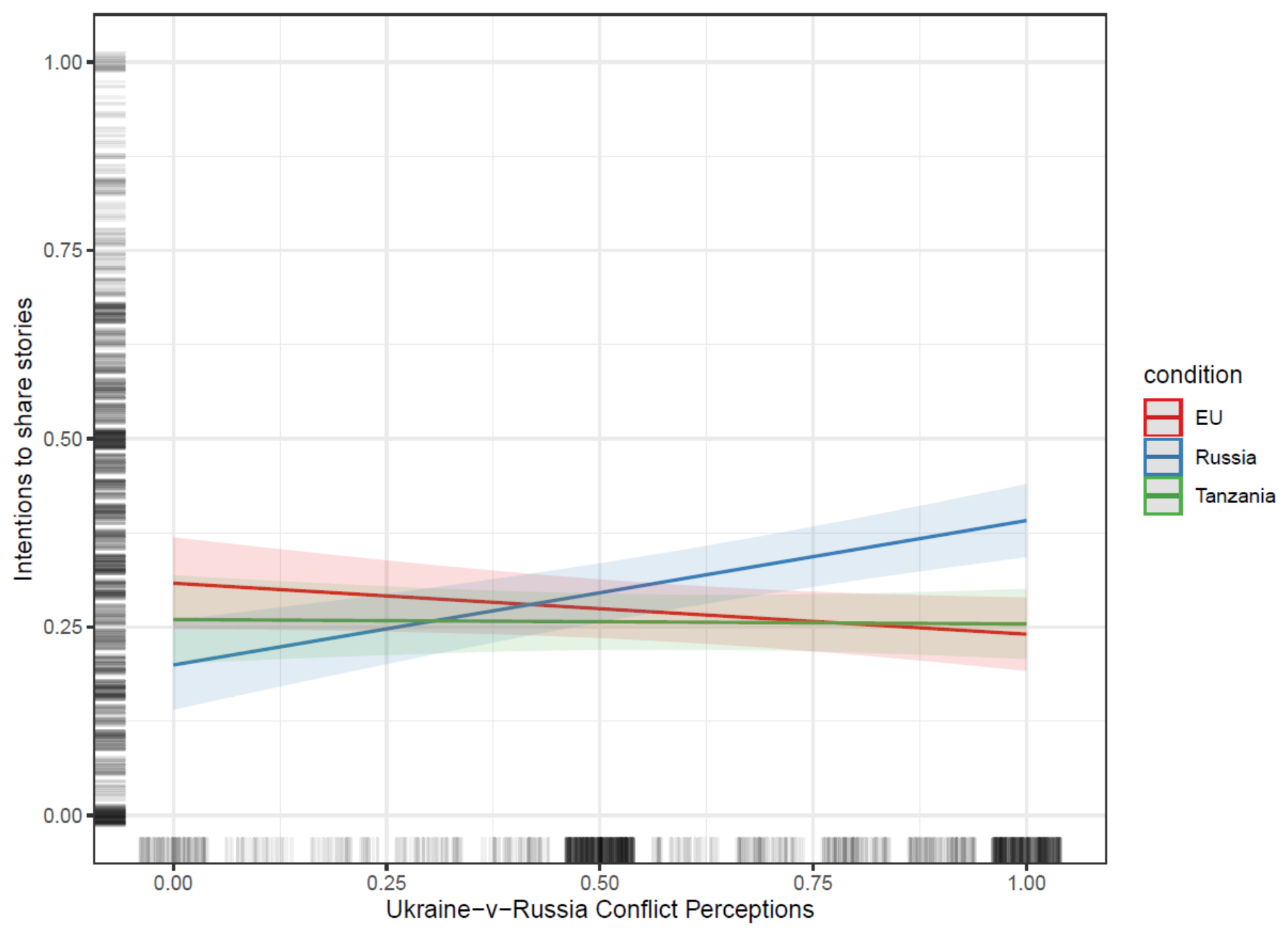

Fig. 3. Predicted values of intentions to share the fake news stories with $95 \%$ confidence intervals by treatment condition -- the EU (red), Russia (blue) and Tanzania (green) -- across the range of conflict perceptions between Ukraine and Russia. Predicted values are based on OLS regression models. The vertical and horizontal lines to the left and at the bottom present the jittered distribution of the dependent variable and conflict perceptions, respectively. Conflict perceptions between Ukraine and Russia range from 0 to 1, with higher values indicating stronger perceptions of conflict. The dependent variable range from 0 to 1 , with higher values indicating stronger beliefs the stories are true. The model adjusts for age, gender, educational level, employment status, political interest and Ukrainian identification, and perceptions of Russian power as well as the interactions between treatment conditions and the covariates.

\section{Group identity, power asymmetries, and knowledge}

The results presented above show that conflict perceptions predict fake news endorsement after adjusting for participants' national identity, political knowledge, and perceptions of power asymmetries between Ukraine and Russia - variables that earlier studies have highlighted in analyses of fake news uptake. Our key finding, however, should not be taken to mean that these other factors 
are irrelevant for people's decisions to accept fake news. Fig. 4, shown below, is based on the regression models used to construct Fig. 2 and Fig. 3. It shows how beliefs (left-hand panels) and intentions to share (right-hand panels) fake news depend on national identity, political knowledge, and perceptions of power when adjusting for conflict perceptions.

The upper panels of Fig. 4 reveal results that fully align with a group-oriented motivated reasoning account wherein people believe and share information congruent with their group identity. Thus, participants with a strong Ukrainian identity are more likely to believe $(\beta=.16, p<.001)$ and share $(\beta=.09, \mathrm{p}<.01)$ the anti-Russian fake news than participants with a weak identity. In contrast, participants who identify with Ukraine are less likely to believe $(\beta=-.09, p=.07)$ and share $(\beta=$ $.21, \mathrm{p}<.001)$ fake news about the EU. Ukrainian identity, finally, is not associated with beliefs and intentions to share fake news about Tanzania.

However, we do not find evidence that people who perceive Russia to be stronger than Ukraine are more likely to endorse anti-Russian fake news. In contrast, as Fig. 4's middle panels show, perceptions that Russia is stronger than Ukraine make participants more likely to believe $(\beta=$ $.15, \mathrm{p}<.001)$ and share $(\beta=.09, \mathrm{p}=.02)$ anti-EU fake news but less willing to believe $(\beta=-.14, \mathrm{p}<$ $.001)$ and share $(\beta=-.14, p<.001)$ anti-Russian fake news. These findings are inconsistent with the expectation that people mostly endorse fake news about competing groups when these groups are perceived to be powerful.

Further, the lower panels show that while political knowledge does not condition the treatment effects, participants with higher levels of political knowledge are generally less likely to endorse fake news. For beliefs in fake news, the association is only modest. Across conditions, moving from the lowest to the highest level of political knowledge is associated with a 7-11 percentage point drop in fake news beliefs $(p$ 's $>.09)$. In contrast, we observe a much stronger and negative association between political knowledge and intentions to share fake news. In all conditions, 
participants with the highest level of knowledge are about 20-23 percentage point less likely to indicate they will share fake news $(p$ 's $<.001)$. Insofar political knowledge reflects concerns over whether information is true or false, the results suggest that beliefs and decisions to share not only rest on group-fueled motivations. Accuracy motivations matter too. Taken together, these results show that factors emphasized in earlier work are able to influence the belief in and sharing of fake news (although, in the case of perceptions of power asymmetries, not in the expected direction). Still, these findings do not take away the main conclusion of this paper: receptivity to fake news varies predictably, depending on how well the story content fits with a person's perceptions of conflict. In this way, our results add important new theory insights into who are more or less susceptible to the influence of fake news. Directional processing of information is not just a function of the strength of group identity; it in large part depends on intergroup dynamics and perceptions of whether group relationships are peaceful or antagonistic. 

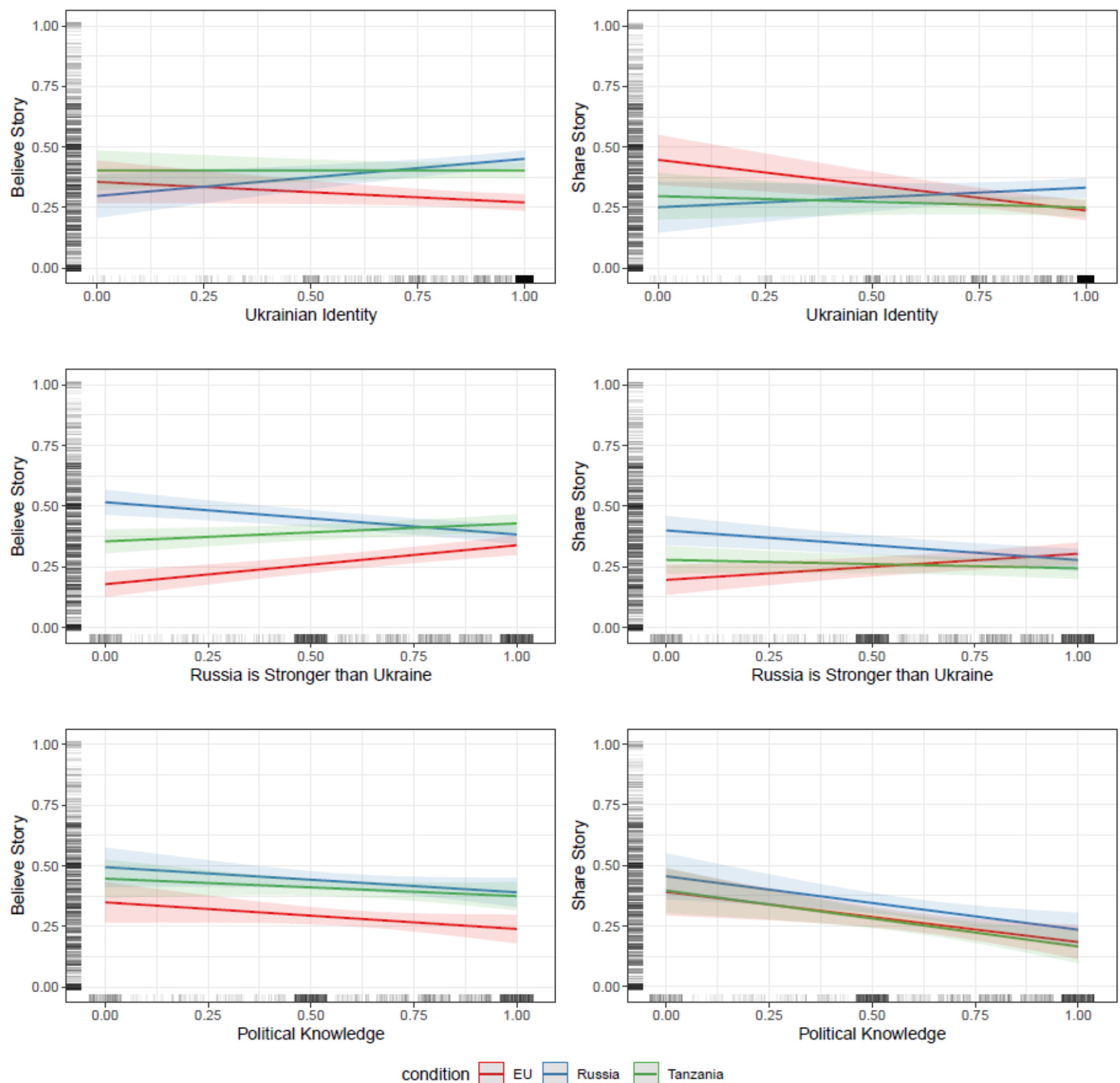

Fig. 4. Predicted values of believing and intentions to share the fake news with $95 \%$ confidence intervals by treatment condition and across the range of Ukrainian identity (upper panels), perceptions of power asymmetry (middle panels) and political knowledge (lower panels). Predicted values are based on OLS regression models. Ukrainian Identity, perceptions of power asymmetry and political knowledge range from 0 to 1 . The dependent variables range from 0 to 1 , with higher values indicating stronger beliefs the stories are true and stronger intentions of sharing the news stories. The models adjust for age, gender, educational level, employment status, political interest and perceptions of conflict between Russia and Ukraine as well as the interactions between treatment conditions and the covariates. 


\section{Conclusion}

Eastern Europe has emerged as a key battleground for misinformation campaigns related to the increasing conflict between Russia, on the one hand, and NATO and the European Union, on the other hand. For these reasons, it is of utmost importance to examine how citizens in Eastern Europe respond to fake news. The particular context of Eastern Europe allows us to get a fuller picture of the factors that shape susceptibility to this type of misinformation. To identify these factors, our manuscript integrates theories of motivated reasoning into the study of fake news endorsement and extends prior studies to more precisely identify who is most likely to engage in the motivated processing of fake news.

Our findings demonstrate that perceptions of conflict between Ukraine and Russia are a major predictor of fake news uptake among our sample of Ukrainian participants. Ukrainians who perceived Russia and their home-country's interests to clash were likely to endorse fake news that denigrates Russia but rejected anti-European fake news narratives. While previous studies have emphasized the role of group identities in igniting motivated reasoning processes, the findings we present show that conflict perceptions operate over and beyond the strength of national identity. Group identities, in other words, become a stronger motivational force when linked to perceptions of inter-group conflict.

To be sure, the present study is not without limitations. Our results rest on observational measures of conflict perceptions, and the usual (but important) caveats regarding causal identification applies here. Though we did take steps to strengthen our ability to cast our findings in causal terms e.g., by adjusting for a series of covariates that earlier research highlights as important - we cannot definitively rule out missing confounders. The ideal study, of course, would experimentally induce higher or lower levels of conflict perceptions and track the downstream effects on fake news beliefs. However, such an experimental study would be both practically and ethically challenging. 
These caveats notwithstanding, we believe that the present findings have important implications. They demonstrate that theories of motivated reasoning can successfully be applied to understand the psychology of those exposed to misinformation campaigns in Eastern Europe and, potentially, beyond. Importantly, we show that conflict perceptions are crucial for fake news uptake. Furthermore, our findings inform discussions about how to counter the effects of misinformation campaigns and the circulation of fake news. Fake news becomes powerful only to the extent people believe the stories they read and want to share them with others. Reducing conflict perceptions, then, could constrain processes of motivated reasoning and help limit the circulation of and exposure to fake news online and on social media in particular. While appealing, this approach comes with an inherent limitation. Conflict perceptions do not appear out of thin air, but often stem from hard-tochange societal and geopolitical divides. Accordingly, solutions to the diffusion of fake news in the context of Eastern Europe will likely call for larger attempts to reverse decades of escalating intergroup conflict. This is much easier said than done when de-escalation often does not align with the interests of political elites. Nevertheless, the de-escalation of societal divides might be a more general guiding principle for groups and institutions that aim to prevent misinformation from spreading.

\section{References}

Altay, S., Hacquin, A. S., \& Mercier, H. (2019). Why do so few people share fake news? It hurts their reputation. New Media \& Society, 1461444820969893.

Beissinger, M. R. (2013). The semblance of democratic revolution: Coalitions in Ukraine's orange revolution. American Political Science Review, 107(3), 574-592.

Berinsky, A (2017). Rumors and health care reform: Experiments in political misinformation. British Journal of Political Science 47(2): 241-262. 
Bhavnani, Ravi, Michael G. Findley, and James H. Kuklinski. (2009). Rumor Dynamics in Ethnic Violence. The Journal of Politics 71 (3):876-92.

Chaisty, P., \& Whitefield, S. (2020). How challenger parties can win big with frozen cleavages: Explaining the landslide victory of the Servant of the People party in the 2019 Ukrainian parliamentary elections. Party Politics, 1354068820965413.

Clark, C. J., Liu, B. S., Winegard, B. M., \& Ditto, P. H. (2019). Tribalism is human nature. Current Directions in Psychological Science, 28(6), 587-592.

Druckman, J. N., Peterson, E., \& Slothuus, R. (2013). How elite partisan polarization affects public opinion formation. American Political Science Review, 107(1), 57-79.

Ecker, U., Hogan, J., \& Lewandowsky, S. (2017). Reminders and Repetition of Misinformation: Helping or Hindering Its Retraction? Journal of Applied Research in Memory and Cognition, $6,185-192$.

Frear, M., \& Mazepus, H. (2021). Security, Civilisation and Modernisation: Continuity and Change in the Russian Foreign Policy Discourse. Europe-Asia Studies, 73(7), 1215-1235.

Fredheim, R. (2015). Filtering foreign media content: How Russian news agencies repurpose Western news reporting. Journal of Soviet and Post-Soviet Politics and Society, 1(1), 37-82.

Golovchenko, Y., Hartmann, M., \& Adler-Nissen, R. (2018). State, media and civil society in the information warfare over Ukraine: citizen curators of digital disinformation. International Affairs, 94(5), 975-994.

Graham, M. H., \& Svolik, M. W. (2020). Democracy in America? Partisanship, Polarization, and the Robustness of Support for Democracy in the United States. American Political Science Review, 114(2), 392-409.

Greenhill, K.M, and B. Oppenheim (2017). Rumos Has It: The Adoption of Unverified Information in Conflict Zones. International Studies Quarterly: 1-17 
Henrich, Joseph. The weirdest people in the world: How the west became psychologically peculiar and particularly prosperous. Farrar, Straus and Giroux, 2020.

Horowitz, D., and A. Varshney (2003). Lethal Ethnic Riots: Lessons from India and Beyond. Us Institute of Peace Special Report 101. Washington, DC.

Iyengar, S., Sood, G., \& Lelkes, Y. (2012). Affect, Not Ideology: A Social Identity Perspective on Polarization. Public Opinion Quarterly, 76(3), 405-431.

Jaccard, J. (2001). Interaction effects in logistic regression (Vol. 135). Sage University Paper Series on Quantitative Applications in the Social Sciences, 07-135.

Kahan, D. M. (2013). Ideology, motivated reasoning, and cognitive reflection. Judgment and Decision Making, 8(4), 407-424.

Kunda, Ziva. 1990. “The Case for Motivated Reasoning.” Psychological Bulletin 108(3): 480-98.

Lazer, D. M., Baum, M. A., Benkler, Y., Berinsky, A. J., Greenhill, K. M., Menczer, F., ... \& Zittrain, J. L. (2018). The science of fake news. Science, 359(6380), 1094-1096.

Miller, J. M., Saunders, K. L., \& Farhart, C. E. (2016). Conspiracy endorsement as motivated reasoning: The moderating roles of political knowledge and trust. American Journal of Political Science, 60(4), 824-844.

Nyhan, B, Reifler, J. (2010) When corrections fail: The persistence of political misperceptions. Political Behavior 32: 303-330.

Nyhan, B, Reifler, J., and Ubel, P. (2013). The Hazards of Correcting Myths about Health Care Reform. Medical Care 51(2): 127-132.

Nyhan, B, and Zeitzoff, T. (2018). Conspiracy and Misperception Belief in the Middle East and North Africa. Journal of Politics 80(4): 1400.1404. 
Oates, S. (2016). Russian Media in the Digital Age: Propaganda Rewired. Russian Politics, 1(4), 398417.

Oates, S. (2017). A Perfect Storm: American Media, Russian Propaganda. Current History, 116(792), 282.

Osmundsen, M, Bor, Alexander, Vahlstrup, P.B., Bechmann, A, \& Petersen, M. B. (2021). Partisan Polarization Is the Primary Psychological Motivation behind Political Fake News Sharing on Twitter. American Political Science Review 115(3): 999-1015.

Pennycook, G., \& Rand, D. G. (2019). Cognitive reflection and the 2016 US Presidential election. Personality and Social Psychology Bulletin, 45(2), 224-239.

Petersen, M. B. (2020). The Evolutionary Psychology of Mass Mobilization: How Disinformation and Demagogues Coordinate Rather Than Manipulate. Current Opinion in Psychology, https://doi.org/10.1016/j.copsyc.2020.02.003.

Pew Research Center (2011). Religious Belief and National Belonging in Central and Eastern Europe. $\quad$ http://www.pewforum.org/2017/05/10/religious-belief-and-national-belonging-incentral-and-eastern-europe/

Silverman, D., Kaltenthaler, K., and Dagher, M. (2021). Seeing Is Disbelieving: The Depths and Limits of Factual Misinformation in War. International Studies Quarterly.

Sunstein, C R. (2009). On Rumors: How Falsehoods Spread, Why We Believe Them, What Can Be Done. New York: Farrar, Straus and Giroux.

Szostek, J. (2017). The Power and Limits of Russia's Strategic Narrative un Ukraine: The Role of Linkage. Perspectives on Politics, 15(2): 379-395

Taber, C. S., and M. Lodge. (2006). Motivated Skepticism in the Evaluation of Political Beliefs. American Journal of Political Science 50(3): 755-69 
Uscinski, JE, Parent, JM (2014) American Conspiracy Theories. New York, NY: Oxford University Press.

Uscinski, J. E., C. Klofstad, and M. D. Atkinson (2016). What Drives Conspiratorial Beliefs? The Role of Informational Cues and Predispositions. Political Research Quarterly 69(1): 57-71.

Van der Linden, S., Roozenbeek, J., \& Compton, J. (2020). Inoculating Against Fake News About COVID-19. Frontiers in Psychology, 11, 2928.

Zajonc, R. B. (1968). Attitudinal effects of mere exposure. Journal of personality and social psychology, 9, 1 . 